\title{
FORMULASI KRIM EKSTRAK ETANOL DAUN KELOR (Moringa oleifera Lamk)
}

\author{
${ }^{1}$ Patihul Husni, ${ }^{2}$ Alika Nuansa Pratiwi, ${ }^{2}$ Ardian Baitariza \\ ${ }^{1}$ Departemen Farmasetika dan Teknologi Farmasi, Fakultas Farmasi, Universitas Padjadjaran, \\ Jl. Raya Bandung Sumedang KM.21, Jatinangor 45363 \\ ${ }^{2}$ Program Studi Farmasi, Fakultas Matematika dan Ilmu Pengetahuan Alam, Universitas Al-Ghifari, \\ Jl. Cisaranten Kulon No.140, Bandung, 40292

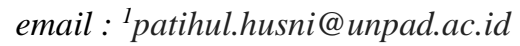

\begin{abstract}
ABSTRAK
Salah satu tanaman berkhasiat antiinflamasi adalah tanaman kelor (Moringa oleifera Lamk) sehingga berpotensi dibuat sediaan krim. Tujuan penelitian ini yaitu untuk mendapatkan formula terbaik krim mengandung ekstrak etanol daun kelor (Moringa oleifera Lamk). Penelitian dilakukan dengan membuat sediaan krim dengan tiga formula berbeda (F1, F2 dan F3) yang mengandung ekstrak daun kelor $10 \%$ b/b. Evaluasi sediaan krim dilakukan selama 4 minggu penyimpanan meliputi uji organoleptik (warna, aroma dan bentuk), homogenitas, $\mathrm{pH}$, viskositas, daya tercuci, tipe krim, dan uji iritasi. Hasil penelitian menunjukkan bahwa seluruh formula (F1, F2 dan F3) memenuhi syarat krim yang baik dan tidak mengiritasi. Formula krim yang paling baik berdasarkan uji penyimpanan selama 4 minggu adalah F3 dengan komposisi formula berupa ekstrak daun kelor 10\%, asam stearat $10 \%$, paraffin cair $2 \%$, setil alkohol $2 \%$, span $801,5 \%$, tween $803,5 \%$, gliserin 7,5\%, titan dioksida 0,7\%, oleum rosae 15 tetes, nipagin 0,18\%, nipasol 0,02\%, aquadest add 50\% b/b.
\end{abstract} Kata Kunci: Krim, ekstrak, daun kelor, antiinflamasi

\begin{abstract}
Moringa oleifera Lamk, the plant that has efficacy as anti-inflammatory agent, is potential to be made as cream preparation. The study aimed to to get the best cream formula containing leaf extract of Moringa oleifera Lamk. The study was conducted by making cream preparations with three different formulas (F1, F2 and F3) containing 10\% w/w Moringa leaf extract. Evaluation of cream preparations carried out for 4 weeks of storage included organoleptic tests (color, odor and consistensy), homogeneity, $\mathrm{pH}$, viscosity, washability, cream type, and irritation test. The results showed that all formulas (F1, F2 and F3) met the requirements of good and non-irritating creams. The best cream formula based on 4 weeks storage study was F3 containing Moringa leaf extract 10\%, stearic acid 10\%, liquid paraffin $2 \%$, cetyl alcohol 2\%, span $801.5 \%$, tween $803.5 \%$, glycerin $7.5 \%$, titanium dioxide $0.7 \%$, oleum rosae 15 drops, nipagin $0.18 \%$, nipasol $0.02 \%$, and aquadest add $50 \%$ w/w.
\end{abstract}

Keywords: Cream, Moringa oleifera Lamk, extract, antiimflammatory

\section{PENDAHULUAN}

Pengobatan menggunakan obat tradisional sudah sangat popular di masyarakat (Wijaya, 1995). Salah satu tanaman dalam pengobatan antiinflamasi adalah tanaman kelor (Moringa oleifera Lamk) yang merupakan tanaman ordo brassicales (Mardiana, 2013). Hampir semua bagian tanaman dapat digunakan dalam pengobatan tradisional. Daun dan tunas muda tanamannya dapat digunakan sebagai sayur, bagian akar dan kulit akar dianggap sebagai anti scorbutic dan dapat digunakan untuk mengurangi iritasi. Bagian 
daunnya memiliki khasiat sebagai antitumor, hipotensi, antioksidan, antiinflamasi, radio-protektif, dan bersifat diuretik (Rathi, 2006). Tanaman kelor mengandung 46 jenis antioksidan dan lebih dari 90 nutrisi. Selain itu, ada 36 senyawa antiinflamasi (Mardiana, 2013).

Untuk lebih memudahkan masyarakat dalam penggunaan obat tradisional, maka dibuat sebuah sediaan. Salah satu sediaan topikal adalah krim. Krim adalah bentuk sediaan setengah padat berupa emulsi kental mengandung tidak kurang dari $60 \%$ air, dimaksudkan untuk pemakaian luar dengan cara dioleskan pada bagian kulit yang sakit (Anief, 1999). Dua tipe krim yaitu krim tipe minyak dalam air (m/a) dan air dalam minyak $(\mathrm{a} / \mathrm{m})$.

Sediaan krim m/a mempunyai pengaruh dalam jumlah dan kecepatan zat aktif yang diabsorpsi. Zat aktif dalam sediaan krim masuk ke dalam basis atau zat pembawa yang akan membawa obat untuk kontak pada permukaan kulit. Beberapa keuntungan sediaan krim diantaranya lebih mudah diaplikasikan, nyaman digunakan, tidak lengket dan mudah dicuci dengan air, dibandingkan dengan sediaan salep, gel dan pasta. Selain itu, basis krim tipe m/a dapat meningkatkan dan memperbaiki kelembaban kulit sehingga kandungan air pada kulit lebih baik dan kulit pun menjadi kenyal dan lentur.
Penggunaan krim yang mengandung ekstrak etanol daun kelor ini secara topikal diharapkan dapat mengurangi inflamasi yang terjadi pada kulit. Oleh karena itu, tahapan awal yang perlu dilakukan adalah pengembangan sediaan krim yang stabil secara fisik.

\section{METODE PENELITIAN}

\subsection{Alat}

Alat yang digunakan adalah cawan penguap, waterbath, mortar, rotary evaporator, kertas saring, pipet tetes, spatel, sudip, batang pengaduk, tabung reaksi (Pyrex) beaker glass $50 \mathrm{ml}$ (Pyrex), timbangan analitik, $\mathrm{pH}$ meter (Lutron), dan viskometer Brookfiled.

\subsection{Bahan}

Daun kelor (Moringa oleifera Lamk.), etanol 96\%, asam stearat, adeps lanae, paraffin cair, trietanolamin, setil alkohol, gliserin, span 80, tween 80, nipagin, nipasol, oleum rosae, titan dioksida, dan aquadest.

\subsection{Metoda}

\subsubsection{Pengumpulan Bahan Tanaman}

Tanaman diambil dari kebun Percobaan Tanaman Obat Manoko, Lembang, Kab. Bandung Barat.

\subsubsection{Determinasi Tanaman}

Determinasi tanaman dilakukan di Laboratorium Biologi Fakultas Matematika dan Ilmu Pengetahuan Alam Universitas Padjajaran, Jatinangor, Sumedang. 


\subsubsection{Pembuatan Ekstraksi Daun Kelor}

Maserasi menggunakan pelarut etanol 96\% merupakan metode ekstraksi yang digunakan. Daun kelor dicuci bersih dan dikeringkan dengan cara diangin-anginkan tanpa sinar matahari langsung. Dilakukan maserasi dengan pelarut etanol 96\% dengan perbandingan $500 \mathrm{~g}$ bahan dalam $4500 \mathrm{ml}$ pelarut dan didiamkan 72 jam (diganti setiap 24 jam selama 3 hari). Dilakukan penyaringan atau filtrasi dengan menggunakan kertas saring. Kemudian hasil ekstraksi dipekatkan menggunakan vacuum rotary evaporator dan didapatkan ekstrak kental daun kelor (Ananto, dkk., 2015). Ekstrak daun kelor kental yang diperoleh ditimbang dan dilakukan perhitungan rendemen.

$\%$ Rendemen $=\frac{\text { Bobot Ekstrak }}{\text { Bobot Awal Simplisia }} \times 100 \%$

\subsubsection{Skrining Fitokimia}

\section{a. Pemeriksaan Alkaloid}

$1 \mathrm{ml}$ sampel ditambah dengan 5 tetes kloroform dan beberapa tetes pereaksi Mayer dan Wagner. Sampel positif mengandung alkaloid jika terbentuk endapan putih ketika ditambah pereaksi Mayer dan endapan coklat ketika ditambah pereaksi Wagner (Harbone, 2006). b. Pemeriksaan Flavonoid

Sampel ditambahkan serbuk magnesium dan $2 \mathrm{ml} \mathrm{HCl}$ didiamkan selama 1 menit, ditambahkan 10 tetes $\mathrm{HCl}$ pekat membentuk warna merah intensif menandakan adanya flavonoid (Harbone, 2006).

\section{c. Pemeriksaan Tanin}

Sampel ditambahkan beberapa tetes $\mathrm{FeCl}_{3} 1 \%$. Sampel positif mengandung tannin apabila menghasilkan warna hijau kebiruan (Harbone, 2006).

\section{d. Pemeriksaan Saponin}

Sampel dimasukkan dalam tabung reaksi, kemudian ditambahkan air panas dan dikocok dengan cepat. Timbulnya busa yang stabil hingga lebih dari 10 menit menunjukkan adanya saponin (Harbone, 2006).

\section{e. Pemeriksaan Steroid dan Terpenoid}

Sampel dimasukkan dalam tabung reaksi, kemudian ditambahkan $\mathrm{CH}_{3} \mathrm{COOH}$ glacial dan $\mathrm{H}_{2} \mathrm{SO}_{4}$ pekat. Terbentuknya warna merah menunjukkkan adanya terpenoid sedangkan warna biru atau ungu menunjukkan adanya steroid (Harbone, 2006). 


\subsubsection{Formulasi Sediaan Krim Ekstrak Daun Kelor}

Tabel 1. Formulasi Krim

\begin{tabular}{cccc}
\hline Nama Bahan & \multicolumn{3}{c}{ Jumlah $(\mathbf{\%} \mathbf{b} / \mathbf{b})$} \\
\cline { 2 - 4 } Ekstrak Etanol Daun Kelor & F1 & F2 & F3 \\
Asam Stearat & 10 & 10 & 10 \\
Adeps Lanae & 7,25 & 6 & 10 \\
Setil Alkohol & 1,5 & - & - \\
Span 80 & - & 2 & 2 \\
Tween 80 & - & - & 1,5 \\
Gliserin & - & - & 3,5 \\
Parafin Cair & - & 7,5 & 7,5 \\
TEA & 12,5 & - & 2 \\
Nipagin & 1,5 & 1,5 & - \\
Nipasol & 0,18 & 0,18 & 0,18 \\
Oleum rosae & 0,02 & 0,02 & 0,02 \\
Titan dioksida & 15 tetes & 15 tetes & 15 tetes \\
Aquadest & 0,7 & 0,7 & 0,7 \\
& add 50 & add 50 & add 50 \\
\hline
\end{tabular}

\subsubsection{Cara Pembuatan Sediaan Krim}

Semua bahan yang diperlukan ditimbang, kemudian fase minyak (F1: parafin cair, adeps lanae, asam stearate dan nipasol. F2: asam stearat, setil alkohol, dan nipasol. F3: asam stearat, setil alkohol, paraffin cair, span 80 dan nipasol) dalam cawan penguap dipanaskan diatas waterbath dengan suhu $70^{\circ} \mathrm{C}$ sampai melebur. Fase air (F1: trietanolamin, nipagin dan aquadest. F2: TEA, gliserin, nipagin dan aquadest. F3: gliserin, tween 80, nipagin dan aquadest) dipanaskan diatas waterbath pada suhu $70^{\circ} \mathrm{C}$ sampai melebur. Fase minyak dipindahkan ke dalam mortir dan ditambahkan fase air serta diaduk sampai dingin dan terbentuk masa krim yang homogen. Ekstrak daun kelor dicampurkan ke dalam basis krim dan digerus hingga homogen, tambahkan titan dioksida yang sudah dilarutkan dalam air sedikit demi sedikit serta oleum rosae.

\subsubsection{Uji Stabilitas Fisik Sediaan Krim Ekstrak Daun Kelor}

a. Organoleptik

Pengamatan dilakukan secara visual dengan melihat bentuk, warna dan bau. Ini dilakukan untuk mengetahui krim yang dibuat sesuai dengan warna dan bau ekstrak yang digunakan (Arifin., 2010).

\section{b. Homogenitas}

Pengujian homogenitas sediaan diperiksa dengan cara mengoleskan sejumlah sediaan pada kaca yang transparan. Sediaan harus menunjukkan susunan yang homogen dan tidak terlihat adanya butirbutir kasar (Ditjen POM., 1985). 
Formulasi Krim Ekstrak Etanol Daun Kelor...

c. $p H$

pH sediaan krim diukur menggunakan $\mathrm{pH}$ meter pada suhu kamar setiap minggu selama 1 bulan. Pemeriksaan pH merupakan bagian dari kriteria uji fisika kimia untuk memprediksi kestabilan krim. Profil $\mathrm{pH}$ menentukan stabilitas bahan aktif dalam suasana asam atau basa (Lachman dkk., 1994).

\section{d. Viskositas}

Viskositas krim diukur dengan menggunakan viskometer Brookfield dan masing-masing formula direplikasi tiga kali. Sediaan sebanyak 30 gram dimasukan kedalam pot salep ukuran 30 gram, kemudian dipasang spindle dan rotor dijalankan. Hasil viskositas dicatat setelah jarum viskometer menunjukan angka yang stabil setelah lima kali putaran, pengukuran viskositas dilakukan setiap minggu selama 1 bulan (Bayuaji dkk., 2012).

\section{e. Tipe Krim}

Uji tipe krim ini menggunakan metode pewarnaan. Krim dioleskan pada kaca objek, kemudian ditetesi dengan metilen biru dan amati perubahan yang terjadi dengan mikroskop. Jika metilen blue menyebar secara merata, maka tipe krim adalah m/a dan jika metilen biru terpisah, maka tipe krim adalah a/m (Arifin., 2010).

\section{f. Daya Tercuci Krim}

1 gram krim dioleskan pada telapak tangan lalu dicuci menggunakan sejumlah volume. Air dilewatkan dari buret dengan perlahan-lahan, amati secara visual ada atau tidaknya krim yang tersisa pada telapak tangan, volume air yang terpakai dicatat (Jellinek., 1970).

\section{g. Uji Iritasi}

0,1 gram krim dioleskan pada kulit lengan bagian dalam kemudian ditutupi dengan kain kasa dan plester. Gejala yang ditimbulkan dilihat setelah 24 jam pemakaian. Jumlah panelis yang digunakan adalah 6 orang. Uji dilakukan selama tiga hari berturut-turut (Ditjen POM., 1985).

\section{HASIL DAN PEMBAHASAN}

\subsection{Determinasi Tanaman}

Hasil determinasi menunjukkan bahwa tanaman yang digunakan pada penelitian ini adalah (Moringa oleifera Lam.) dengan nama lokal kelor. Tujuan determinasi adalah utuk membuktikan kebenaran tanaman yang digunakan dalam penelitian.

\subsection{Pembuatan Ekstrak Daun Kelor}

Ekstraksi daun kelor dilakukan dengan menggunakan metode maserasi. Hal ini dikarenakan lebih mudah dilakukan bisa dibandingkan dengan metode yang lain. Selain itu, metode maserasi hanya menggunakan alat yang sederhana, menghasilkan rendemen yang tinggi serta tidak merusak metabolit sekunder karena tidak dilakukan proses pemanasan (Nirwana dkk., 2015; Sari dkk., 2014). Pemilihan pelarut etanol $96 \%$ karena merupakan pelarut yang bersifat universal yang dapat 
melarutkan senyawa polar, nonpolar dan semi polar sehingga dengan menggunakan etanol $96 \%$ zat aktif yang diperlukan dapat tertarik sepenuhnya (Febriani., 2014).

Setelah dilakukan maserasi maka dilakukan proses penyaringan dengan menggunakan kertas saring. Kemudian hasil ekstraksi dipekatkan menggunakan rotary evaporator hingga didapatkan ekstrak kental daun kelor (Ananto dkk., 2015). Maserat yang dipekatkan mengahasilkan 97,5 g dengan rendemen ekstrak sebesar 19,5\%. Ekstrak kental daun kelor disimpan dalam wadah terlindung dari cahaya langsung.

\subsection{Skrining Fitokimia}

Skrinning fitokimia dilakukan untuk mengetahui ada atau tidak adanya metabolit sekunder dalam simplisia dan ekstrak. Hasil skrining (Tabel 2) menunjukkan bahwa sampel daun kelor positif mengandung senyawa alkaloid, flavonoid, tannin, saponin, steroid/terpenoid. Hal ini menunjukkan bahwa senyawa metabolit sekunder yang terkandung dalam daun kelor tertarik oleh pelarut.

Tabel 2. Skrining Fitokimia

\begin{tabular}{lcc}
\hline \multicolumn{1}{c}{$\begin{array}{c}\text { Metabolit } \\
\text { Sekunder }\end{array}$} & Simplisia & Ekstrak \\
\hline Alkaloid & Positif & Positif \\
Flavonoid & Positif & Positif \\
Tanin & Positif & Positif \\
Saponin & Positif & Positif \\
Steroid/Terpenoid & Positif & Positif \\
\hline
\end{tabular}

\subsection{Formulasi Sediaan Krim Ekstrak Daun Kelor}

Pada formulasi F1 dan F2 akan terbentuk emulgator TEA-stearat yang merupakan reaksi antara asam stearate dan Trietanolamin (TEA). Emulgator ini terbentuk melalui reaksi penyabunan (safonifikasi). Sedangkan, pada F3 emulgator yang digunakan berupa emulgator sintentik yaitu kombinasi surfaktan non ionik tween 80 dan span 80 . Emulgator yang terbentuk akan menyatukan fase minyak dan fase air serta bahan lainnya sehingga terbentuk krim.

\subsection{Uji Stabilitas Fisik Sediaan Krim Ekstrak Daun Kelor}

\subsubsection{Organoleptik}

Semua formula menghasilkan krim berwarna hijau kecolatan, bau mawar, dan berbentuk semisolid. Hasil pengamatan organoleptik pada ketiga formulasi krim (Tabel 3) menunjukkan bahwa selama 4 minggu penyimpanan tidak mengalami perubahan sediaan krim dari bentuk, warna dan bau krim. Hal ini dikarenakan selama masa penyimpanan sediaan krim tersimpan dalam wadah yang tertutup rapat dan terlindung dari cahaya langsung.

\subsubsection{Homogenitas}

Sediaan krim yang dihasilkan bersifat homogen. Hasil uji homogenitas (Tabel 3) menunjukkan bahwa ketiga formula sediaan krim secara umum tetap homogen selama penyimpanan. Namun, F1 mengalami 
pemisahan fase pada hari ke-28. Hal ini disebabkan oleh ketidakstabilan emulgator sehingga terjadi pemisahan fase minyak dengan fase air.

Tabel 3. Uji Organoleptik dan Homogenitas $(n=3)$

\begin{tabular}{cccccc}
\hline Formula & Hari Ke- & Warna & Bau & Bentuk & Homogenitas \\
\hline \multirow{4}{*}{ F1 } & 0 & Hijau kecoklatan & Mawar & Semisolid & Homogen \\
& 7 & Hijau kecoklatan & Mawar & Semisolid & Homogen \\
& 14 & Hijau kecoklatan & Mawar & Semisolid & Homogen \\
& 21 & Hijau kecoklatan & Mawar & Semisolid & Homogen \\
& 28 & Hijau kecoklatan & Mawar & Semisolid & Pemisahan Fase \\
& 0 & Hijau kecoklatan & Mawar & Semisolid & Homogen \\
F2 & 7 & Hijau kecoklatan & Mawar & Semisolid & Homogen \\
& 14 & Hijau kecoklatan & Mawar & Semisolid & Homogen \\
& 21 & Hijau kecoklatan & Mawar & Semisolid & Homogen \\
& 28 & Hijau kecoklatan & Mawar & Semisolid & Homogen \\
& 0 & Hijau kecoklatan & Mawar & Semisolid & Homogen \\
F3 & 7 & Hijau kecoklatan & Mawar & Semisolid & Homogen \\
& 14 & Hijau kecoklatan & Mawar & Semisolid & Homogen \\
& 21 & Hijau kecoklatan & Mawar & Semisolid & Homogen \\
& 28 & Hijau kecoklatan & Mawar & Semisolid & Homogen \\
\hline
\end{tabular}

\subsubsection{Uji pH}

Hasil pemeriksaan $\mathrm{pH}$ krim (Gambar 1) diperoleh $\mathrm{pH}$ berkisar antara 5,7-7,5. $\mathrm{pH}$ sediaan krim tersebut memenuhi syarat $\mathrm{pH}$ sediaan topikal yang aman untuk kulit yaitu 4-8 (Magdalena dkk., 2016). pH semua formula sediaan krim relatif stabil selama masa penyimpanan. Pemeriksaan $\mathrm{pH}$ dilakukan menggunakan $\mathrm{pH}$ meter dan dilakukan selama satu bulan pada suhu kamar.

\subsubsection{Uji Viskositas}

Viskositas krim berkisar antara 300014.500 cps (3000-5500 (F1), 3000-4000 (F2), 9000-14.500 (F3)). Perbedaan viskositas pada masing-masing formula dipengaruhi oleh perbedaan komposisi formula. Gambar 2 menunjukkan bahwa viskositas krim F3 mengalami peningkatan.
Hal ini disebabkan penambahan bahan peningkat viskositas yaitu setil alkohol dan penggunaan emulgator nonionik (span 80 dan tween 80) yang menghasilkan krim yang stabil dalam kondisi asam, basa dan $\mathrm{pH}$ netral sehingga emulgator ini akan menghasilkan krim yang stabil ketika dicampurkan dengan ekstrak (Hamzah, dkk., 2014).

\subsubsection{Uji Tipe Krim}

Semua formula krim ekstrak etanol daun kelor memiliki tipe m/a. Hasil pemeriksaan tipe krim menggunakan metilen blue yang dapat larut dalam air dan tidak larut dalam minyak. Metilen blue akan tersebar merata setelah diteteskan pada selapis krim tipe m/a. 


\subsubsection{Daya Tercuci Krim}

1 gram krim dapat dicuci dengan baik oleh aquadest sebanyak $30 \mathrm{ml}(\mathrm{F} 1), 23 \mathrm{ml}$ (F2) dan $20 \mathrm{ml}$ (F3) berturut-turut. Daya tercuci ini berkaitan dengan tipe krim minyak dalam air $(\mathrm{m} / \mathrm{a})$ yang akan lebih mudah tercuci dibandingkan dengan tipe air dalam minyak $(\mathrm{a} / \mathrm{m})$.
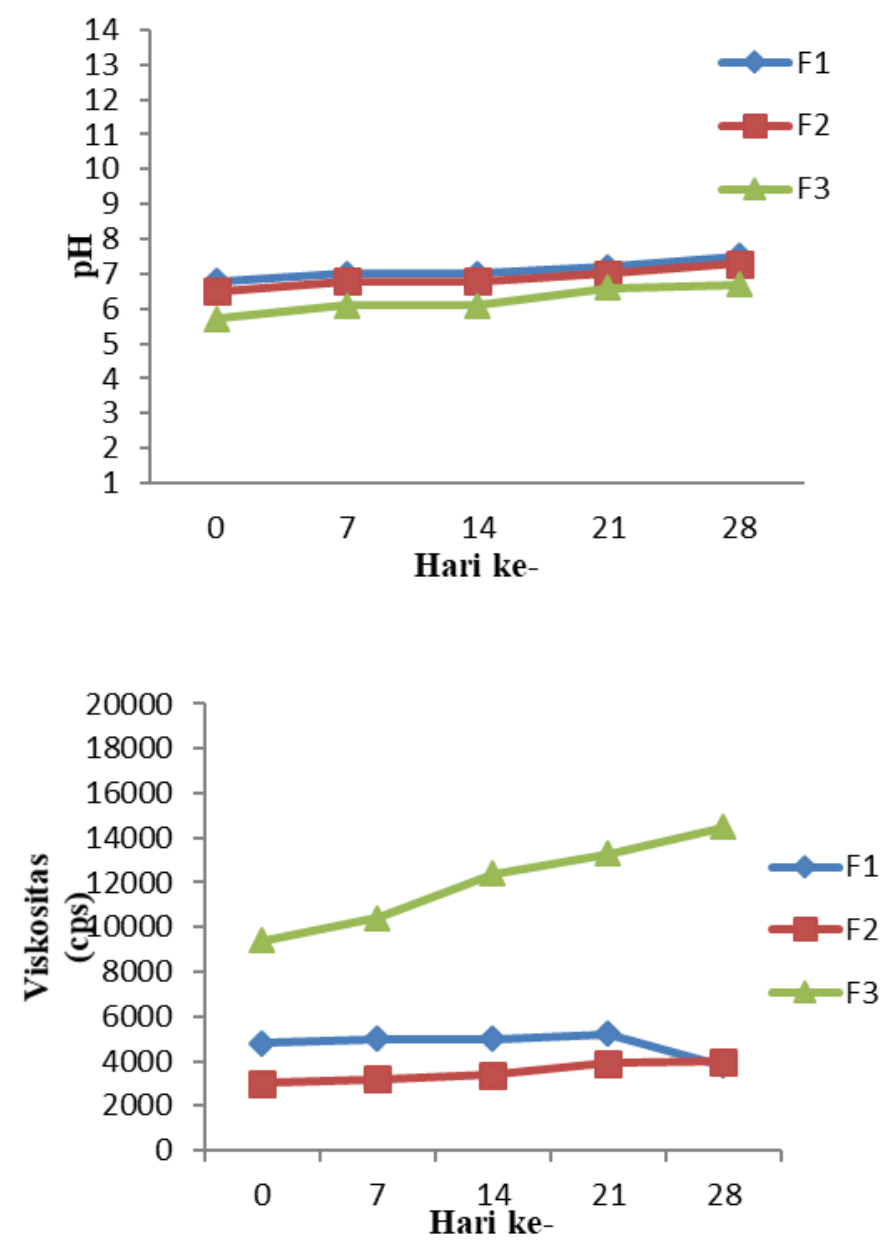

Gambar 2. Hasil uji viskositas $(n=3)$

\subsubsection{Uji Iritasi}

vesikula dan edema pada kulit. Hasil

Semua formula krim tidak pemeriksaan uji iritasi pada 6 orang panelis mengakibatkan iritasi pada kulit panelis tertera pada Tabel 4.

karena tidak menimbulkan eritema, papula,

Tabel 4. Uji Iritasi Krim $(n=6)$

\begin{tabular}{ccccccc}
\hline \multirow{2}{*}{ Formula } & \multicolumn{7}{c}{ Pengamatan Iritasi Responden } \\
\cline { 2 - 7 } & 1 & 2 & 3 & 4 & 5 & 6 \\
\hline F1 & - & - & - & - & - & - \\
F2 & - & - & - & - & - & - \\
F3 & - & - & - & - & - & - \\
\hline
\end{tabular}

Keterangan: - = tidak mengiritasi 


\section{KESIMPULAN}

Formula krim ekstrak daun kelor (Moringa oleifera Lam) yang paling baik berdasarkan uji penyimpanan selama 4 minggu adalah F3 dengan komposisi formula berupa ekstrak daun kelor $10 \%$, asam stearat $10 \%$, paraffin cair $2 \%$, setil alkohol 2\%, span 80 1,5\%, tween 80 3,5\%, gliserin $7,5 \%$, titan dioskida $0,7 \%$, oleum rosae 15 tetes, nipagin $0,18 \%$, nipasol 0,02\%, aquadest add 50\% b/b.

\section{DAFTAR PUSTAKA}

Anief, Moh., 1999. Ilmu Meracik Obat. Gadjah Mada University Press. Yogyakarta.

Arifin HI., 2010. Formulasi Krim Anti Jerawat Ekstrak Lidah Buaya (Aloe vera (L.) Burm.f) Terhadap Staphyloccus aureus dan Staphyloccus epidermidis. Skripsi. Fakultas Matematika dan Ilmu Pengetahuan Alam Universitas Al-Ghifari. Bandung.

Ananto FJ, Herwanto ES, Nugrahandhini NB, Najwa YC, dan Abidin MZ., 2015. Gel Daun Kelor Sebagai Antibiotik Alami Pada Pseudomonas aeruginosa Secara In Vivo. PHARMACY, 12(1).

Bayuaji TS, Astuti IY, dan Dhiani BA., 2012. Aktivitas Antifungi Krim Daun Ketepeng Cina (Senna alata L. Roxb.) Terhadap Trichophyton mentagrophytes. Pharmacy. 09(3).

Carter JS. 1975. Dispensing for Pharmaceutical Student $12^{\text {th }} \mathrm{Ed}$. Pitman Medical. London.

Ditjen POM., 1985. Formularium Kosmetika Indonesia, Departemen Kesehatan Republik Indonesia. Jakarta.

Nurida FW., 2014. Aktivitas Antibakteri Ekstrak Etanol dan Fraksi-Fraksi dari Ekstrak Etanol Daun Kelapa Sawit (Elaeis guineensis Jacq) Terhadap
Bakteri Staphylococcus aureus dan Bacillus subtilis Serta Profil KLTnya. Naskah Publikasi. Fakultas Farmasi. Universitas Muhammadiyah Surakarta.

Harbone JB., 2006. Metode Fitokimia, Penentuan Cara Modern Menganalisis Tumbuhan. Penerjemah Dr. K. Padmawinata. Bandung: Penerbit ITB.

Nursalam H, Isriany I, dan Aulia SAD., 2014. Pengaruh Emulgator Terhadap Aktivitas Antioksidan Krim Ekstrak Etanol Kelopak Bunga Rosella (Hibiscus sabdariffa Linn). Jurnal Kesehatan.7(2).

Jellinek JS., 1970. Formulation and Function Of Cosmetics. Willey Interscience, New York.

Lachman L, Lieberman HA, dan Kanig JL., 1994. Teori dan Praktek Farmasi Industri Jilid I Edisi II. Penerjemah Siti Suyatmi. Penerbit Universitas Indonesia. Jakarta.

Magdalena AB, Bardi S, Indriyanti W, dan Maelaningsih SF., 2016. Formulasi Krim Antihiperpigmentasi Ekstrak Kulit Buah Delima (Punica granatum L.). Fakultas Farmasi. Universitas Padjadjaran. 3(1).

Mardiana L., 2013. Daun Ajaib Tumpas Penyakit. Penerbit Swadaya. Jakarta.

Nirwana AP, Astirin OP, dan Widiyani T., 2015. Skrining Fitokimia Ekstrak Etanol Daun Benalu Kersen (Dendrophtoe pentandra L. Miq.). El vivo. 3(2): 12.

Putri SN., 2015. Formulasi Sediaan Krim Tabir Surya Ekstrak Teh Putih (Camellia sinensis L.Ok)., Prosiding Penelitian SPeSIA. Farmasi FMIPA. Universitas Islam Bandung.

Rathi BS, Bodhankar SL, dan Baheti AM., 2006. Evaluation of Aqueous Leaves Extract of Moringa oleifera Linn for Wound Healing In Albino Rats. Indian Journal of Experimental Biology. 4:898-901.

Sari EM, Maruf WF, dan Sumardianto., 2014. Kajian Senyawa Bioaktif 
Ekstrak Teripang Hitam (Holothuria Edulis) Basah dan Kering Sebagai Antibakteri Alami. Jurnal Pengolahan dan Bioteknologi Hasil Perikanan. 3(4): 17 .

Sharon N, Anam S, dan Yuliet., 2013. Formulasi Krim Antioksidan Ekstrak Etanol Bawang Hutan (Eleutherine palmifolia L. Merr. Jurnal of Natural Science. 2(3):111-122.

Voigth R., 1994. Buku Pelajaran Teknologi Farmasi, Edisi Kelima. Penerjemah Drs. Soendani Noerono. Gadjah Mada University Perss. Yogyakarta.

Widyaningrum N, dan Karuniaekawati S., 2009. Pengaruh Variasi Konsentrasi Ekstrak Etanolik Daun Teh Hijau (Camelia sinensis L.) Dalam Sediaan Krim Terhadap Sifat Fisik dan Aktivitas Antibakteri. Jurnal Ilmu Farmasi dan Farmasi Klinik. 6(1).

Wijaya KH., 1995. Tanaman Berkhasiat Obat Jilid II. Pustaka Kartini. Jakarta.

Yenti R, Afrianti R, dan Afriani L., 2011. Formulasi Krim Ekstrak Etanol Daun Kirinyuh (Euphatorium odoratum. L) untuk Penyembuhan Luka. Majalah Kesehatan PharmaMedika. 3(1):227. 